\title{
Stable isotope analysis of dissolved organic carbon in soil solutions using a catalytic combustion total organic carbon analyzer-isotope ratio mass spectrometer with a cryofocusing interface
}

\author{
I. De Troyer $^{1 *}$, S. Bouillon ${ }^{1}$, S. Barker ${ }^{2}$, C. Perry ${ }^{3}$, K. Coorevits ${ }^{1}$ and R. Merckx ${ }^{1}$ \\ ${ }^{1}$ Division Soil and Water Management, Department of Earth and Environmental Sciences, Katholieke Universiteit Leuven, Kasteelpark Arenberg \\ 20, 3001 Heverlee, Belgium \\ ${ }^{2}$ SerCon Limited, 3b Crewe Trade Park, Gateway, Crewe CW1 6JT, UK \\ ${ }^{3}$ Analytical Sciences Limited, 51 Newnham Road, Cambridge CB3 9EY, UK
}

Received 11 May 2009; Revised 29 November 2009; Accepted 30 November 2009

\begin{abstract}
Stable carbon isotopes are a powerful tool to assess the origin and dynamics of carbon in soils. However, direct analysis of the ${ }^{13} \mathrm{C}^{12} \mathrm{C}$ ratio in the dissolved organic carbon (DOC) pool has proved to be difficult. Recently, several systems have been developed to measure isotope ratios in DOC by coupling a total organic carbon (TOC) analyzer with an isotope ratio mass spectrometer. However these systems were designed for the analysis of fresh and marine water and no results for soil solutions or ${ }^{13} \mathrm{C}$-enriched samples have been reported. Because we mainly deal with soil solutions in which the difficult to oxidize humic and fulvic acids are the predominant carbon-containing components, we preferred to use thermal catalytic oxidation to convert $\mathrm{DOC}$ into $\mathrm{CO}_{2}$. We therefore coupled a high-temperature combustion TOC analyzer with an isotope ratio mass spectrometer, by trapping and focusing the $\mathrm{CO}_{2}$ cryogenically between the instruments. The analytical performance was tested by measuring solutions of compounds varying in the ease with which they can be oxidized. Samples with DOC concentrations between 1 and $100 \mathrm{mg} C / \mathrm{L}$ could be analyzed with good precision (standard deviation (SD) $\leq 0.6 \%$ ), acceptable accuracy, good linearity (overall $S D=1 \%$ ) and without significant memory effects. In a ${ }^{13} \mathrm{C}$-tracer experiment, we observed that mixing plant residues with soil caused a release of plant-derived DOC, which was degraded or sorbed during incubation. Based on these results, we are confident that this approach can become a relatively simple alternative method for the measurement of the ${ }^{13} \mathrm{C} /{ }^{12} \mathrm{C}$ ratio of DOC in soil solutions. Copyright (C) 2010 John Wiley \& Sons, Ltd.
\end{abstract}

Dissolved organic matter plays an important role in soil genesis and in the transport of soil pollutants with a high affinity for organic matter. ${ }^{1}$ Therefore, it is important to take this dissolved organic carbon (DOC) pool into account when studying carbon $(\mathrm{C})$ dynamics. The origin and dynamics of organic $\mathrm{C}$ in soil are frequently studied with tracer experiments. In ${ }^{13} \mathrm{C}$-tracer experiments at natural abundance level, as well as with enriched samples, the ${ }^{13} \mathrm{C} /{ }^{12} \mathrm{C}$ ratios of soil organic carbon and $\mathrm{CO}_{2}$ have been measured routinely. However, direct analysis of the ${ }^{13} \mathrm{C} /{ }^{12} \mathrm{C}$ isotope ratio of the DOC of a soil solution has remained more elusive until recently.

Several techniques have been proposed to measure the ${ }^{13} \mathrm{C} /{ }^{12} \mathrm{C}$ isotope ratio of DOC. The earlier methods were based on the 'off-line' oxidation of DOC using different methods, followed by the analysis of the evolved $\mathrm{CO}_{2}$ by

*Correspondence to: I. De Troyer, Division Soil and Water Management, Department of Earth and Environmental Sciences, Katholieke Universiteit Leuven, Kasteelpark Arenberg 20, 3001 Heverlee, Belgium.

E-mail: inne.detroyer@gmail.com dual-inlet isotope ratio mass spectrometry (IRMS). ${ }^{2}$ Le Clercq et al., ${ }^{3}$ for example, used supercritical oxidation to determine ${ }^{13} \mathrm{C} /{ }^{12} \mathrm{C}$ ratios of marine DOC. The $\mathrm{CO}_{2}$ resulting from the oxidation of the sample at $650^{\circ} \mathrm{C}$ and 350 bars was cryogenically trapped in a vacuum vessel and analyzed on a dual-inlet IRMS instrument with precisions of about $1 \%$ in the $\delta^{13} \mathrm{C}$ value and $3 \%$ in the DOC concentration. Fry et al. ${ }^{4}$ determined the isotope composition of marine DOC by hightemperature, sealed-tube combustion of the dried sample and analysis of the evolved $\mathrm{CO}_{2}$ by IRMS. The standard deviations of the measured replicates ranged from 0.1 to $0.7 \%$, because of several types of blank problems. In another study, stream water samples were concentrated by rotary evaporation, dried in silver cups and analyzed on an elemental analyzer (EA) coupled to an IRMS instrument. ${ }^{5}$ Soil solutions were analyzed in a comparable way by evaporation of acidified solutions at $50^{\circ} \mathrm{C}$ and analysis of the residue. ${ }^{6}$ Although these techniques were more reliable, they still were very complex and sample preparation was timeconsuming. More recently, however, automated systems for the measurement of the $\delta^{13} \mathrm{C}$ value of dissolved organic 
carbon $\left(\delta^{13} \mathrm{C}_{\mathrm{DOC}}\right)$ have been developed, coupling commercially available aqueous total organic carbon (TOC) instruments with continuous-flow IRMS. ${ }^{7-9}$ These automated systems were used successfully to determine the ${ }^{13} \mathrm{C} /{ }^{12} \mathrm{C}$ isotope ratio of dissolved organic and inorganic carbon (DOC and DIC) in freshwater samples ${ }^{7}$ and of DOC in marine water samples. 8 However, their suitability for soil solution samples was not examined or reported. The latter methods use wet oxidation to convert DOC into $\mathrm{CO}_{2}$ which can be measured by IRMS. This technique has a high sensitivity at low levels, due to the possibility of measuring large sample sizes. However, oxidation is more difficult and can become incomplete when samples contain high concentrations of more refractory organic carbon compounds such as humic and fulvic acids. ${ }^{10}$ Because organic carbon in soil solutions mainly consists of these components, it is preferable to analyze DOC in soil solutions by high-temperature combustion. High-temperature combustion (HTC) analyzers also use smaller sample volumes than wet oxidation (WO) instruments. This is another important advantage when working with soil solutions, since it is difficult to collect large volumes of pore water from soil samples. Thus, in order to determine the ${ }^{13} \mathrm{C} /{ }^{12} \mathrm{C}$ isotope ratio of DOC components in soil solution, we preferred to couple an aqueous TOC analyzer using HTC with a continuous-flow IRMS instrument. To be able to measure the small amount of $\mathrm{CO}_{2}$, resulting from low DOC concentrations combined with small sample volumes, the gas stream was cryogenically trapped and focused before the measurement on the IRMS instrument. A comparable linking of an HTC TOC instrument and an IRMS instrument, where the $\mathrm{CO}_{2}$ is trapped between them, has been described for the analysis of marine and freshwater samples. ${ }^{11,12}$ Lang et al. ${ }^{11}$ cryogenically trapped the $\mathrm{CO}_{2}$ resulting from the oxidation of a $100 \mu \mathrm{L}$ sample. In this way, the $\delta^{13} \mathrm{C}$ of seawater DOC could be measured with an error of $\pm 0.8 \%$. However, this technique was not completely automated and it was quite time-consuming because many rinses of the system were necessary to minimize the errors. Panetta et al. ${ }^{12}$ also used cryogenic trapping to couple an HTC TOC instrument with an IRMS instrument. With their online set-up, samples could be analyzed with a $\delta^{13} \mathrm{C}_{\mathrm{DOC}}$ accuracy of $\pm 0.2 \%$ and precision of $\pm 0.3 \%$ ( $1 \mathrm{SD}$ ); but the analysis of one sample, including the rinsing step, required around $7 \mathrm{~mL}$ of sample. Both systems were, however, specifically set up for the analysis of marine and freshwater samples with low DOC concentrations (0.5-25 mg C/L) at natural abundance level.

The main drawback of working with HTC TOC analyzers is the contribution of a significant blank ${ }^{13}$ which is the result of an instrument blank and a blank caused by the reagents used. ${ }^{14}$ The instrument blank can originate from carbonaceous compounds contained in the catalyst material, ${ }^{15,16}$ impurities in the carrier gas, tubing or leaks in the system. ${ }^{11}$ Apart from the instrument blank, the reagents used to dilute or acidify samples can also contain organic impurities and cause a background signal. ${ }^{14}$ Since the total blank can differ between systems and as such affect the results, it is important to take it into account. ${ }^{17}$ Therefore, Panetta et al. ${ }^{12}$ suggested including a blank correction when measuring the ${ }^{13} \mathrm{C} /{ }^{12} \mathrm{C}$ ratios of DOC. However, a blank correction seemed not to be necessary for samples exceeding $7 \mathrm{mg} \mathrm{C} / \mathrm{L}$, which is the case in most of our samples. Bisutti et al. ${ }^{10}$ also mentioned large memory effects as a disadvantage of dry combustion methods. The carry-over effect on the DOC concentrations seemed not to be significant in the set-up of Panetta et al., ${ }^{12}$ but data about the memory effect on $\delta^{13} \mathrm{C}_{\mathrm{DOC}}$ values could not be found. Nevertheless, this should be examined when ${ }^{13} \mathrm{C}$-enriched samples are analyzed.

Almost no results have been reported for soil solutions or ${ }^{13} \mathrm{C}$-enriched samples. As mentioned earlier, problems with low sample volumes are associated with the analysis of pore water samples, rather than problems with low concentrations and high blank contributions. Thus, there were different concerns when coupling a TOC analyzer with an IRMS instrument to measure natural abundance or enriched soil solution samples. In this paper we describe all the modifications needed to couple an HTC TOC instrument with a cryotrapping device and continuous-flow IRMS in order to determine DOC and $\delta^{13} C_{\text {DOC }}$ in soil solution samples. Furthermore, the analytical conditions and the analytical performance of this set-up are presented as are the results of a preliminary tracer experiment with ${ }^{13} \mathrm{C}$-enriched straw.

\section{EXPERIMENTAL}

\section{General set-up}

The set-up consists of a catalytic combustion TOC analyzer for analyzing solutions (Thermalox TOC-TN; Analytical Sciences Ltd., Cambridge, UK) coupled to a continuous-flow IRMS instrument (20-20; SerCon Ltd., Crewe, UK). Between the two instruments, a cryotrapping device (CRYOPREP system; SerCon Ltd.) traps the $\mathrm{CO}_{2}$ from the effluent gas stream of the TOC analyzer before transferring it to the IRMS instrument at a lower carrier gas flow rate. Only a few modifications were necessary to install this set-up.

\section{Carrier gas}

The TOC instrument normally uses clean air at a flow rate of $180 \mathrm{~mL} / \mathrm{min}$ and needs at least some oxygen for the combustion. In contrast, the IRMS instrument only works on helium at low flow rates. In the hyphenated system, a mixture of $\mathrm{He}\left(99.999997 \%\right.$ purity) and $\mathrm{O}_{2}$ (99.99998\% purity) is used as the carrier gas for the TOC instrument, while the cyrofocusing unit and subsequent transfer of $\mathrm{CO}_{2}$ to the IRMS instrument uses ultrapure He only. Therefore, two mass flow controllers are installed in the TOC instrument, resulting in a He flow rate of $120 \mathrm{~mL} / \mathrm{min}$ and an $\mathrm{O}_{2}$ flow rate of $7 \mathrm{~mL} / \mathrm{min}$. These gas flows are mixed and used as the carrier gas for the TOC instrument, even when it is used as a standalone instrument.

\section{Sample injection}

In order to have sufficient $\mathrm{CO}_{2}$ supplied to the IRMS instrument, larger sample volumes (aliquots) are used for the coupled system than for TOC standalone measurements. In this set-up, we currently use aliquots of $160 \mu \mathrm{L}$. To ensure complete oxidation, this large aliquot is injected in four steps at $1 \mathrm{~s}$ intervals. 
Software

Both software packages controlling the instruments needed to be modified. A specific software package (Callisto CFIRMS version 4.0.40 for EuropaNT + TOC_CRYOPREP, supplied by SerCon Ltd.) was installed to automate the coupled system. This software controls the CRYOPREP and IRMS systems, opens/closes the valve between the TOC and the CRYOPREP and sends a start/stop signal to the software of the TOC instrument. The software controlling the TOC instrument (Thermalox Environmental, supplied by Analytical Sciences Ltd.) was modified to accept the start/stop signal of the Callisto software and modify the timing of the condensate drain to prevent large pressure changes. The amount of $\mathrm{CO}_{2}$ produced is measured by a non-dispersive infrared (NDIR) detector of the TOC instrument and can also be determined from the response on the IRMS instrument.

A general scheme of the analytical method is given in Fig. 1. For analysis, the sample is injected into the total carbon (TC) reactor, which is filled with Pt-coated quartz rods and heated to $680^{\circ} \mathrm{C}$. The carrier gas $\left(95 \% \mathrm{He}+5 \% \mathrm{O}_{2}\right)$ flows through the two reactors and sweeps the $\mathrm{CO}_{2}$ resulting from

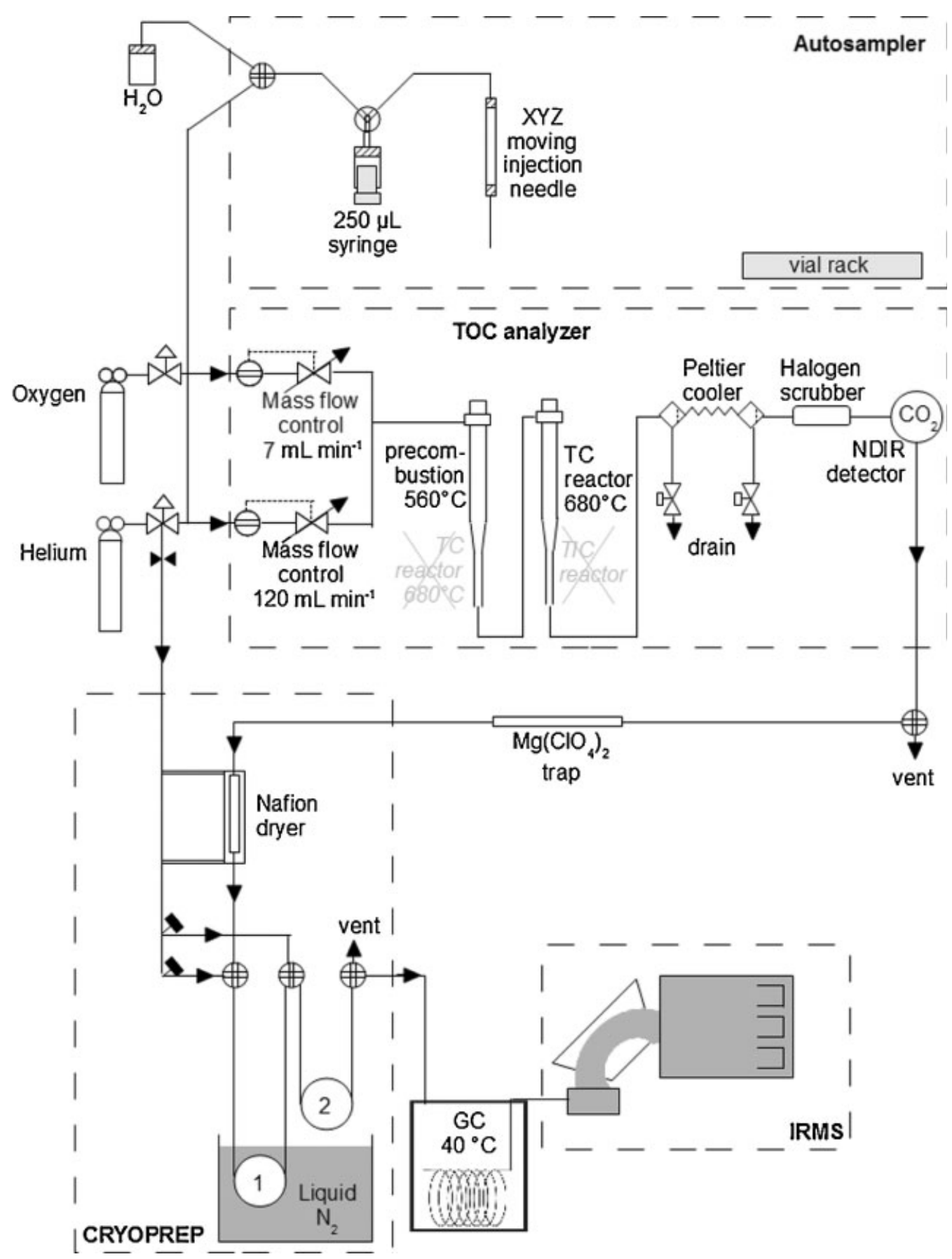

Figure 1. Schematic diagram of the system. The set-up consisted of a TOC analyzer with autosampler (Thermalox TOC-TN; Analytical Sciences Ltd., UK) coupled to a CRYOPREP system (SerCon Ltd., UK) and a continuous-flow IRMS instrument (20-20; SerCon Ltd., UK). The original set-up of the reactors is given in grey and italic. 
the sample combustion to a number of gas cleanup elements. The aqueous gas stream is first dehumidified by a Peltier cooler, halogens are scrubbed out using brass wool (mainly $\mathrm{Cu}$ ) and $\mathrm{CO}_{2}$ is then measured using an NDIR detector. The effluent of the TOC instrument is led to the CRYOPREP interface. The $\mathrm{CO}_{2}$ is first cryogenically trapped by immersing the first loop of the CRYOPREP system in liquid $\mathrm{N}_{2}$ for 695 s. Once the $\mathrm{CO}_{2}$ has been effectively trapped from the sample, the first loop is removed from the liquid $\mathrm{N}_{2}$, while a second loop is immersed. The $\mathrm{CO}_{2}$ of the sample is flushed from loop 1 with $\mathrm{He}$ as carrier gas at a flow rate of $20 \mathrm{~mL} / \mathrm{min}$ and is focused on loop 2. The sample is condensed into a small volume to enhance chromatography. Finally, loop 2 is defrosted and the $\mathrm{CO}_{2}$ is transferred with a lower He flow rate $(2 \mathrm{~mL} / \mathrm{min}$ ) through a gas chromatography (GC) column (Poraplot-Q at $40^{\circ} \mathrm{C}$; in order to separate $\mathrm{CO}_{2}$ from $\mathrm{N}_{2} \mathrm{O}$ ) to the IRMS instrument.

In the IRMS method, a pulse of $\mathrm{CO}_{2}$ monitoring gas is directly introduced into the ion source prior to each sample peak and is used for a first indicative calculation of the $\delta^{13} \mathrm{C}$ value of the sample (see 'Calibration' below). The analysis of one sample, including the pulse of monitoring gas, takes around $22 \mathrm{~min}$, but the entire measurement procedure (acidification, purging of inorganic $\mathrm{C}, \ldots$ ) is completely automated.

\section{Additional modifications to improve analytical performance}

The system as described above proved to be useful for the measurement of the ${ }^{13} \mathrm{C} /{ }^{12} \mathrm{C}$ ratio of DOC in soil solutions. However, after a first testing period, some supplementary modifications were carried out to improve the quality of the measurements (Fig. 1).

\section{The TOC instrument tubing}

In the TOC instrument Teflon tubing was used generally. To avoid atmospheric $\mathrm{CO}_{2}$ diffusion through this tubing and consequently to minimize the blank, all the polymer tubing after the TC reactor was replaced by stainless steel tubing.

\section{Precombustion of the carrier gas}

Because we did not use the instrument to analyze inorganic carbon, the total inorganic carbon (TIC) reactor was used to precombust the carrier gas. The acid in the standard reactor was changed to a catalyst (Pt-coated quartz rods), and the reactor was heated at $560^{\circ} \mathrm{C}$ and placed before instead of after the TC reactor. Any $\mathrm{CO}_{2}$ resulting from this precombustion treatment was trapped using a soda-lime $\mathrm{CO}_{2}$ trap.

\section{Magnesium perchlorate trap}

During the automated analysis of large batch runs, the Peltier cooler was not always sufficient to dehumidify the gas stream from the TC reactor. In that case, dehumidification of the gas stream by the Nafion dryer before entering the IRMS instrument was effective most of the time. However, to reduce the water vapour load of the Nafion dryer, an extra magnesium perchlorate trap was installed between the TOC instrument and the CRYOPREP system.

\section{Sample preparation and injection system}

Because we only want to measure the isotopic ratio of the organic carbon, inorganic carbon is removed from the samples before analysis. Therefore, $\mathrm{HCl}(2.5 \mathrm{M}, 8 \mu \mathrm{L}$ for $2 \mathrm{~mL}$ of sample) is first added to all samples in the vial rack and afterwards all samples are purged with $\mathrm{He}$ (90 s at a flow rate of $\sim 300 \mathrm{~mL} / \mathrm{min}$ ), i.e. the method measures all nonpurgeable organic carbon (NPOC). This is automatically done by the autosampler (AS8000 XYZ, Analytical Sciences Ltd.) of the TOC instrument. A glass barrel with injection needle is connected to the autosampler's moveable arm, and is operated by a $250 \mu \mathrm{L}$ ceramic syringe pump using a threeway valve. The third port of the valve is connected to another valve which can switch between an inflow of rinsing water and He (Fig. 1). For the acidification of the samples, the glass barrel draws in a certain amount of $2.5 \mathrm{M} \mathrm{HCl}$, moves to the vial rack and adds $8 \mu \mathrm{L}$ of $\mathrm{HCl}$ to each sample. Subsequently, the samples are, one by one, purged by He for $90 \mathrm{~s}$ at a flow rate of $\sim 300 \mathrm{~mL} / \mathrm{min}$. The analysis by the HTC TOC-IRMS set-up is only started after acidifying and purging all samples. Therefore, an exact amount $(160 \mu \mathrm{L}$ in this case) of the sample is drawn into the glass barrel and injected into the TC reactor.

\section{Data analysis}

Data on isotope values are reported as per mil (\%) deviations from the international standard Vienna Peedee Belemnite (VPDB):

$$
\delta^{13} \mathrm{C}_{\text {sample }}=\left(\frac{R_{\mathrm{s}}}{R_{\mathrm{st}}}-1\right) \times 1000
$$

where $R_{\mathrm{s}}$ is the ratio of ${ }^{13} \mathrm{C} /{ }^{12} \mathrm{C}$ in the sample and $R_{\mathrm{st}}$ equates to 0.0112372 , the ratio of the VPDB standard.

\section{Calibration}

Before the analysis of a batch of samples on the HTC TOCIRMS system, the TOC instrument is calibrated using solutions of potassium hydrogen phthalate (KHP) at concentrations ranging from 0 to $100 \mathrm{mg} \mathrm{C/L}$. MilliQ water (distilled water filtered by Milli-Q Academic A10; Millipore, Billerica, MA, USA) is used as the zero and all standard solutions are acidified and purged. However, the injection of $160 \mu \mathrm{L}$ of samples containing $50 \mathrm{mg} \mathrm{C} / \mathrm{L}$ or more, results in an amount of $\mathrm{CO}_{2}$ which is out of the NDIR detector range. The areas measured by the TOC analyzer still give an indication of the $\mathrm{C}$ concentration in the solutions, but the accuracy and precision of the analysis are poor. The areas measured by the IRMS instrument in the same calibration can, however, be used to calculate the carbon concentration in the solutions.

The $\delta^{13} \mathrm{C}$ values are calculated from the ion beams measured by the IRMS instrument, relative to the pulses of the $\mathrm{CO}_{2}$ monitoring gas. Since a pulse of monitoring gas is analyzed before each sample, possible drift in the measurements of the IRMS instrument is taken into account. Because no certified reference material for $\delta^{13} \mathrm{C}_{\mathrm{DOC}}$ exists, the certified IAEA-CH6 sucrose $\left(\delta^{13} \mathrm{C}=-10.4 \pm 0.03 \%\right)$ was dissolved in milliQ water at a concentration of $\sim 20 \mathrm{mg} \mathrm{C} / \mathrm{L}$ and used as a reference. In every batch, some subsamples of this reference solution are included to check the accuracy of the measurement and the calculation of the $\delta^{13} \mathrm{C}$ values. 


\section{Blank determination and correction}

As mentioned in the introductory section, TOC analyzers, especially HTC systems, are known to produce a significant blank and therefore a blank correction may be necessary. ${ }^{14,17}$ To investigate the contribution of the blank, we determined both the instrument blank and the milliQ blank directly. The instrument blank was determined by trapping the gas stream of the TOC analyzer for the same length of time as a normal sample run, but without injecting samples. As the reference and testing solutions are prepared by dissolving the compounds in milliQ water, there can also be a blank caused by the presence of carbon-containing substances in the milliQ water. This milliQ blank was determined by direct analysis of acidified and purged milliQ water. Apart from the intensity, we also need to know the $\delta^{13} \mathrm{C}$ value of the blank, because the correction for the blank is based on the mass balance as described in Eqn. (1):

$$
\begin{gathered}
A_{\text {measured }} \times \delta^{13} \mathrm{C}_{\text {measured }}=A_{\text {sample }} \times \delta^{13} \mathrm{C}_{\text {sample }} \\
+A_{\text {blank }} \times \delta^{13} \mathrm{C}_{\text {blank }}
\end{gathered}
$$

whereby $A_{\text {measured }}=A_{\text {sample }}+A_{\text {blank }}$

The intensity of the blank could easily be determined as described above, but the isotopic composition could not be directly measured because the signals were too low for accurate analysis by IRMS. Therefore, the $\delta^{13} \mathrm{C}$ value of the blank was indirectly obtained from the results of a linearity test in which a dilution series of IAEA-CH6 sucrose solutions from 1 to $100 \mathrm{mg} \mathrm{C} / \mathrm{L}$ was analyzed. A deduction of the mass balance results in Eqn. (2):

$$
\begin{aligned}
\delta^{13} \mathrm{C}_{\text {measured }}= & {\left[\left(\delta^{13} \mathrm{C}_{\text {blank }}-\delta^{13} \mathrm{C}_{\text {sample }}\right) \times A_{\text {blank }}\right] } \\
& \times \frac{1}{A_{\text {measured }}}+\delta^{13} \mathrm{C}_{\text {sample }}
\end{aligned}
$$

The real $\delta^{13} \mathrm{C}$ value of the sample can be determined from the $y$-intercept of the least-squares regression analysis in the inset of Fig. 2, in which $\delta^{13} \mathrm{C}$ values were plotted against the inverse of the sample intensity. The regression equation is then used to calculate the $\delta^{13} \mathrm{C}$ signature of the blank, using the measured blank area.

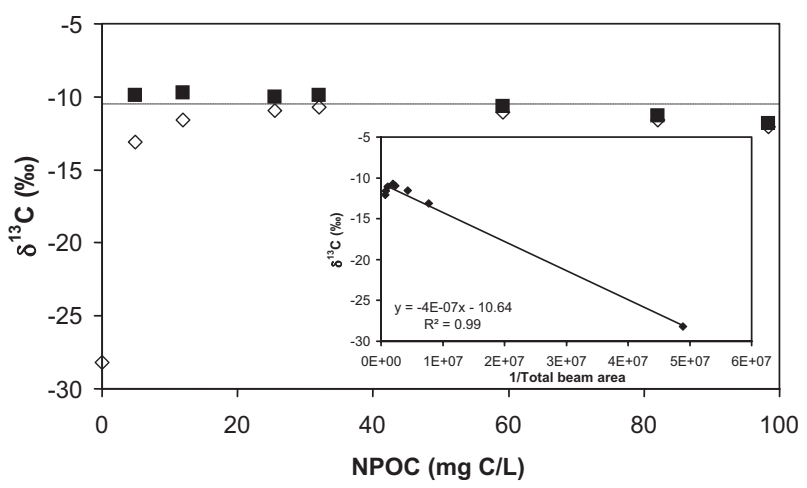

Figure 2. The $\delta^{13} \mathrm{C}$ value of a dilution series of an IAEA-CH6 sucrose solution before $(\diamond)$ and after $(\boldsymbol{\square})$ blank correction. Inset: $\delta^{13} \mathrm{C}$ values expressed against the inverse of the IRMS signal intensity for all data points from the same test, to determine the blank.

\section{Analytical performance}

To investigate the analytical performance of the hyphenated system, the following validation procedures were performed.

\section{Precision and accuracy}

Because no certified reference material for $\delta^{13} \mathrm{C}_{\mathrm{DOC}}$ exists, the certified IAEA-CH6 sucrose $\left(\delta^{13} \mathrm{C}=-10.45 \pm 0.03 \%\right)$ was dissolved in milliQ water at a concentration of $\sim 20 \mathrm{mg} \mathrm{C} / \mathrm{L}$ and used as a reference to test the accuracy of the system. Comparable solutions of other organic carbon-containing compounds, varying in the ease with which they can be oxidized, were prepared. In order to examine the precision of the system, all solutions were repeatedly measured by HTC TOC-IRMS. The carbon concentrations of the solutions were measured on the TOC instrument during the coupled analysis. In addition, the accuracy of the presented system was verified, by measuring a solid sample of the same compounds by EA-IRMS using the certified IAEA-CH6 sucrose as a reference and comparing those results with those of the HTC TOC-IRMS analysis.

\section{Linearity}

Linearity is the capability of the IRMS instrument to produce the same isotopic ratios for varying concentrations of the same sample. Because varying concentrations cause different pressures at which the electron ionization source ionizes the $\mathrm{CO}_{2}$ gas, linearity is not always evident and it is essential to outline the concentration range wherein the IRMS instrument shows acceptable linearity. The linearity of the coupled system was determined by analyzing dilution series of solutions of IAEA-CH6 sucrose $(n=3)$, potassium hydrogen phthalate $(n=2)$, humic acid (Cat. No. H 1675-2; Aldrich, Milwaukee, WI, USA) $(\mathrm{n}=3)$ and fulvic acid (International Humic Substances Society 'IHSS', Suwannee River Fulvic acid; IHSS, St Paul, MN, USA) $(\mathrm{n}=3)$. Finally, two soil solutions were diluted to varying concentrations and analyzed by HTC TOC-IRMS ( $\mathrm{n}=2$ for soil solution $\mathrm{A}$ and $\mathrm{n}=3$ for soil solution $\mathrm{B}$ ).

\section{Influence of adding acid and purging}

The effect of acidifying and purging the samples on $\delta^{13} \mathrm{C}$ values was tested by measuring solutions of IAEA-C6 sucrose, humic acid (Cat. No. H 1675-2, Aldrich) and fulvic acid (IHSS, Suwannee River Fulvic acid). Three identical samples of the solutions ( 10 or $20 \mathrm{mg} \mathrm{C/L}$ ) were measured before and after adding $\mathrm{HCl}(2.5 \mathrm{M}, 8 \mu \mathrm{L}$ for $2 \mathrm{~mL}$ of sample) and purging for $90 \mathrm{~s}$. In a second test, the solutions were mixed with a solution of bicarbonate. The final concentrations were approximately $15 \mathrm{mg} \mathrm{C} / \mathrm{L}$ inorganic carbon and $10 \mathrm{mg} \mathrm{C} / \mathrm{L}$ (fulvic acid) to $20 \mathrm{mg} \mathrm{C} / \mathrm{L}$ (sucrose and humic acid) organic carbon. These carbon concentrations are comparable with the carbon concentrations of the soil solutions typically measured in the laboratory. After acidifying and purging the sample as described above, the total, inorganic and organic carbon concentrations were measured as well as the ${ }^{13} \mathrm{C} /{ }^{12} \mathrm{C}$ ratios of the DOC. 


\section{Memory effect}

The effect of cross-contamination was investigated by measuring a sample of the IAEA-C6 sucrose solution after a natural abundance sample (beet sugar solution, $20 \mathrm{mg} \mathrm{C/L}$, $\delta^{13} \mathrm{C}=-23.7 \%$ ) and after an enriched sample (aqueous extract of enriched maize straw, $13 \mathrm{mg} \mathrm{C} / \mathrm{L}, \delta^{13} \mathrm{C}=340 \%$ ). After both samples, the sucrose solution was measured five times.

\section{System stability over time}

As a longer-term quality control, an internal reference solution was prepared and analyzed within each batch of samples. The reference was prepared by dissolution of $80 \mathrm{mg}$ humic acid (Cat. No. H 1675-2, Aldrich,) in 1 L of milliQ water and filtering it at $0.45 \mu \mathrm{m}$. A small amount of sodium azide $\left(\mathrm{NaN}_{3}, 10 \mathrm{mg} / \mathrm{L}\right)$ was added to prevent degradation of the humic acid in the solution by bacteria. This internal reference solution was stored in a brown, glass bottle at $4^{\circ} \mathrm{C}$. Each time a batch of samples was analyzed on the HTC TOC-IRMS system, one or two subsamples of this internal reference were included in the analysis.

\section{Preliminary tracer experiment with (enriched) soil solutions}

The utility of the system to measure the isotopic ratio of DOC in soil solutions was finally tested by measuring unknown soil solutions. We investigated the effect of plant residues on DOC in soils in a tracer experiment, where ${ }^{13} \mathrm{C}$-enriched straw was added to an agricultural soil sample (Luvisol, Leuven, Belgium) and the amount of labeled DOC was determined during 2 weeks of incubation. The soil, sieved at $4 \mathrm{~mm}$ and stored air-dry, was divided among 30 plastic pots each with $220 \mathrm{~g}$, rewetted till a $55 \%$ filled pore space ratio and stored for 2 days at $4^{\circ} \mathrm{C}$. The enriched maize straw (cob leaves, $44 \% \mathrm{C},{ }^{13} \mathrm{C}$ atom excess $=1.23 \%$ ) was cut into pieces of 2 to $3 \mathrm{~mm}$ and added to half of the soil samples until achieving a final ratio of $5.7 \mathrm{~g} / \mathrm{kg}$ dry soil. The other half of the samples was used as a control. All soil samples were incubated for 2 weeks (aerobic, dark, $22^{\circ} \mathrm{C}$ ). Immediately after adding the residues and after 1, 3, 7 and 14 days of incubation, the soil solution of three samples of each treatment was isolated twice by centrifugation (double chamber, $3500 \mathrm{~g}$ ). To determine the concentration and the isotopic ratio of DOC, the soil solutions were filtered at $0.45 \mu \mathrm{m}$ and measured on the HTC TOC-IRMS system. However, soil solution samples containing more than $50 \mathrm{mg}$ $\mathrm{C} / \mathrm{L}$ DOC were diluted prior to analysis.

\section{RESULTS AND DISCUSSION}

\section{Sample volume}

As discussed in the Introduction, the small injection volume is one of the advantages of the HTC TOC system. In our setup, $160 \mu \mathrm{L}$ of solutions with DOC concentrations ranging from 1 to $100 \mathrm{mg} \mathrm{C} / \mathrm{L}$ is injected. Thus, an amount of 0.16 to $16 \mu \mathrm{g} \mathrm{C}$ is analyzed compared with the 10 to $125 \mu \mathrm{g} \mathrm{C}$ measured by a wet oxidation TOC analyzer coupled to an IRMS instrument. ${ }^{8}$ Because the DOC concentrations in soil solutions are greater than in fresh or marine water, samples also can be diluted to overcome the problem of low sample volumes. However, the milliQ water used to dilute the samples still contains some carbon which leads to a significant blank (see next paragraph). Therefore, injecting small sample volumes of undiluted solutions is preferred. Nevertheless, when low concentration samples $(<10 \mathrm{mg} \mathrm{C} / \mathrm{L})$ have to be measured larger sample volumes can be injected to ameliorate the precision and accuracy of the analysis. If necessary, the $250 \mu \mathrm{L}$ syringe can be replaced by a $1 \mathrm{~mL}$ syringe.

The measurement of $160 \mu \mathrm{L}$ of solutions containing more than $50 \mathrm{mg} \mathrm{C} / \mathrm{L}$ is out of the NDIR detector range, but since the amount of $\mathrm{C}$ is also measured by the IRMS instrument, the DOC concentrations can still be calculated. We generally analyze soil solutions with concentrations of between 10 and $50 \mathrm{mg} \mathrm{C} / \mathrm{L}$. The ${ }^{13} \mathrm{C} /{ }^{12} \mathrm{C}$ isotopic ratio of DOC, on the other hand, was measured with good precision and accuracy, at any concentration between 1 and $100 \mathrm{mg} \mathrm{C/L}$ (see "Analytical performance" below).

\section{Blank determination and correction}

For sample volumes of $160 \mu \mathrm{L}$, the instrument blank was $0.20 \pm 0.01 \mu \mathrm{g} \mathrm{C}$, which is comparable with the blanks described by Panetta et al. ${ }^{12}$ After the additional modifications to reduce the background, the instrument blank decreased to $0.05 \pm 0.01 \mu \mathrm{g} C$. The response of the milliQ samples accounted for $0.31 \pm 0.03 \mu \mathrm{g} \quad \mathrm{C}$ before and $0.24 \pm 0.08 \mu \mathrm{g} C$ after the additional modifications. Thus, contaminations in acidified and purged milliQ caused an extra background of $0.11 \mu \mathrm{g} \mathrm{C}$ to $0.19 \mu \mathrm{g} C$ above the instrument background. Therefore, care should be taken when measuring milliQ blanks or making up solutions in milliQ water. Since we mostly wanted to measure soil solutions with concentrations of between 10 and $50 \mathrm{mg} \mathrm{C/L}$, the total blank contribution ranged from 15 to $1 \%$ and a blank correction appeared to be necessary, especially for low concentration solutions and solutions prepared with milliQ water. Because the samples of the linearity test used to determine the $\delta^{13} \mathrm{C}$ value of the blanks were prepared by dissolving the IAEA-CH6 sucrose in milliQ water, the system blank as well as the milliQ blank should be taken into account. Therefore, the beam area of the milliQ sample was used as the blank in the calculations. The intercept of the linear regression curve of the sample $\delta^{13} \mathrm{C}$ versus the inverse of the beam area (inset Fig. 2) was $-10.6 \pm 0.8 \%$ and this did not significantly differ from the reference value provided by the IAEA $\left(-10.45 \pm 0.03 \%\right.$ ). The resulting $\delta^{13} \mathrm{C}$ value of the milliQ blank, calculated from the slope of this curve (inset Fig. 2) and using the measured beam area of the blank, was $-30.2 \%$. In general, the ${ }^{13} \mathrm{C}$ value of the milliQ blank ranged between -30 and $-22 \%$. This variation was caused by factors such as the number of samples measured since catalyst regeneration, the tuning and source settings of the IRMS instrument and the air temperature in the laboratory. Therefore, it is important to repeat the test regularly in order to detect this kind of drift in the background of the analysis. In the rest of this paper, all measured $\delta^{13} \mathrm{C}$ values of solutions prepared with milliQ water were corrected in this way. In the analysis of soil solutions, only the instrument blank and not the milliQ blank had to be taken into account. However, the instrument blank was rather small compared with the carbon concentrations of most of the soil solutions and consequently this correction had only a limited effect. 
Table 1. Comparison of $\delta^{13} \mathrm{C}$ values of several organic carbon-containing compounds (mean $\pm \mathrm{SD}$ ). Solid samples were measured by EA-IRMS. A solution of the compounds in milliQ water was measured by the new HTC TOC-IRMS system after acidification and purging. The NPOC concentration of the solutions and the difference in $\delta^{13} \mathrm{C}$ values measured by HTC TOC-IRMS and $\mathrm{EA} / \mathrm{IRMS}\left(\Delta \delta^{13} \mathrm{C}\right)$ are also given

\begin{tabular}{|c|c|c|c|c|c|c|c|}
\hline & \multirow[b]{2}{*}{$\begin{array}{c}\text { reference } \delta^{13} \mathrm{C} \\
-\%{ }^{-}\end{array}$} & \multicolumn{2}{|c|}{ EA-IRMS solid } & \multicolumn{3}{|c|}{ HTC TOC-IRMS } & \multirow[b]{2}{*}{$\Delta \delta^{13} \mathrm{C}$} \\
\hline & & $\begin{array}{l}\delta^{13} \mathrm{C} \\
-\% \text { - }\end{array}$ & $\mathrm{n}$ & $\begin{array}{l}\delta^{13} \mathrm{C} \\
-\%{ }^{0}\end{array}$ & $\begin{array}{c}{[\mathrm{NPOC}]} \\
-\mathrm{mg} \mathrm{C} / \mathrm{L}-\end{array}$ & $\mathrm{n}$ & \\
\hline IAEA-CH6 sucrose & $-10.45 \pm 0.03^{\mathrm{a}}$ & & & $-10.4 \pm 0.1$ & $22.6 \pm 0.2$ & 7 & -0.06 \\
\hline IAEA-C6 sucrose & $-10.8 \pm 0.5^{\mathrm{b}}$ & $-10.6 \pm 0.2$ & 3 & $-10.3 \pm 0.2$ & $19.6 \pm 0.2$ & 4 & -0.3 \\
\hline Cane sugar & & $-11.1 \pm 0.2$ & 5 & $-11.5 \pm 0.1$ & $22.6 \pm 0.1$ & 5 & 0.4 \\
\hline Beet sugar & & $-25.4 \pm 0.3$ & 5 & $-25.4 \pm 0.1$ & $22.6 \pm 0.1$ & 5 & 0.0 \\
\hline Potassium phthalate & & $-28.7 \pm 0.1$ & 5 & $-28.2 \pm 0.1$ & $32.5 \pm 0.6$ & 3 & -0.5 \\
\hline Fulvic acid ${ }^{+}$ & $-27.9^{c}$ & $-26.2 \pm 0.3$ & 5 & $-27.5 \pm 0.1$ & $25.6 \pm 0.8$ & 3 & 1.3 \\
\hline Humic acid* & & $-25.0 \pm 0.1$ & 5 & $-25.4 \pm 0.1$ & $29.0 \pm 0.4$ & 3 & 0.4 \\
\hline Soil solution A & & N.D. & & $-26.7 \pm 0.1$ & $34.4 \pm 0.4$ & 2 & \\
\hline Soil solution B & & N.D. & & $-27.0 \pm 0.1$ & $10.0 \pm 0.2$ & 3 & \\
\hline
\end{tabular}

${ }^{*}$ Aldrich, cat. no. H 1675-2; ${ }^{+}$IHSS, Suwannee River Fulvic acid, 1R101F.

${ }^{a}$ Certified reference value, IAEA.

${ }^{\mathrm{b}}$ Informative value, IAEA.

${ }^{\mathrm{c}}$ Informative value provided by IHSS, no SD specified.

N.D. not determined.

\section{Analytical performance}

\section{Precision and accuracy}

Results of the precision and accuracy tests are presented in Table 1. The mean $\delta^{13} \mathrm{C}$ value of the IAEA-CH6 sucrose solution, analyzed by HTC TOC-IRMS, did not differ from the value provided by the IAEA. For most other substances tested, there were no or only small differences between the $\delta^{13} \mathrm{C}$ values of the solid sample (analyzed by EA-IRMS) and the solutions (analyzed by HTC TOC-IRMS). The largest absolute difference in $\delta^{13} \mathrm{C}$ values measured by the two methods was $1.3 \%$. However, the $\delta^{13} \mathrm{C}$ value of the fulvic acid solution measured by HTC TOC-IRMS only differed by $0.4 \%$ from the value given by the IHSS. A least-squares error linear regression between values measured by EA-IRMS and values measured by HTC TOC-IRMS resulted in an $R^{2}$ value of 0.995 and an intercept of $0.04 \%$. With regard to the precision of the analysis by HTC TOC-IRMS, the variation between subsequent carbon concentration measurements was never greater than 3\%. Standard deviations between $\delta^{13} \mathrm{C}$ values of repeated measurements by HTC TOC-IRMS were all $\leq 0.2 \%$, which was comparable with or even slightly better than the EA-IRMS performance. The precision and accuracy were also tested on solutions of fulvic and humic acids because these compounds are more representative of soil solutions. Although these compounds are more difficult to oxidize, the precision and accuracy of the analyses were as good as for the analyses of the sucrose solutions. Finally, unknown soil solutions were repeatedly measured with very good precision ( $\mathrm{SD} \leq 0.1 \%$ ).

\section{Linearity}

Figure 3 illustrates that all individual solutions with DOC concentrations ranging from 1 to $100 \mathrm{mg} \mathrm{C} / \mathrm{L}$ were measured with very good precision. For all samples with DOC concentrations greater than $5 \mathrm{mg} \mathrm{C} / \mathrm{L}$, the $\delta^{13} \mathrm{C}$ values were measured with a SD less than or equal to $0.4 \%$. Solutions with carbon concentrations less than $5 \mathrm{mg} \mathrm{C/L}$ were analyzed with some more variance but the results were still acceptable for the majority of applications (SD $\leq 0.6 \%$ ). Thus, even in a concentration range much larger than the typical range tested before (see Table 1), the ${ }^{13} \mathrm{C} /{ }^{12} \mathrm{C}$ isotopic ratios of DOC in solutions could be measured by HTC TOC/IRMS with an acceptable precision. Moreover, the mean $\delta^{13} \mathrm{C}$ values of the DOC in solutions with concentrations between 1 and $100 \mathrm{mg} \mathrm{C/L}$ did not differ, or only slightly differed, from the value of the solid sample determined by EA/IRMS (Table 1) and the $\mathrm{SD}$ over the whole concentration range was less than or equal to $1 \%$. Hence, for concentrations ranging from 1 to $100 \mathrm{mg} \mathrm{C} / \mathrm{L}$, the system showed acceptable linearity after correction for the background. The linearity of the analysis with and without blank correction is compared in Fig. 2. It can be seen that, in the analysis of solutions with concentrations greater than $20 \mathrm{mg} \mathrm{C} / \mathrm{L}$, a blank correction seemed not to be necessary.

\section{Influence of adding acid and purging}

The solutions of the organic compounds in milliQ water contained a small amount of inorganic carbon ( 1 to $3 \mathrm{mg} \mathrm{C} / \mathrm{L}$; data not shown). Because this inorganic carbon was less depleted than the organic carbon in the samples, the $\delta^{13} \mathrm{C}$ values of the solutions measured with the total carbon (TC) analysis were greater than the reference values or those determined by EA-IRMS (Tables 1 and 2). Because the difference in the ${ }^{13} \mathrm{C} /{ }^{12} \mathrm{C}$ isotopic ratio between the inorganic carbon and the sucrose carbon was smaller, the effect of the inorganic carbon on the $\delta^{13} \mathrm{C}$ value of the sucrose solution was not significant. Adding extra inorganic carbon increased the $\delta^{13} \mathrm{C}$ value of all solutions. After acidifying and purging the samples (NPOC treatment), no inorganic $C$ was left and the $\delta^{13} \mathrm{C}$ value did not significantly differ from the reference values or those determined by EA-IRMS (Tables 1 and 2). For some samples, the precision of the analysis slightly decreased after the NPOC treatment, but was still acceptable ( $\mathrm{SD} \leq 0.4 \%$ ). Hence we concluded that (bi)carbonate species 

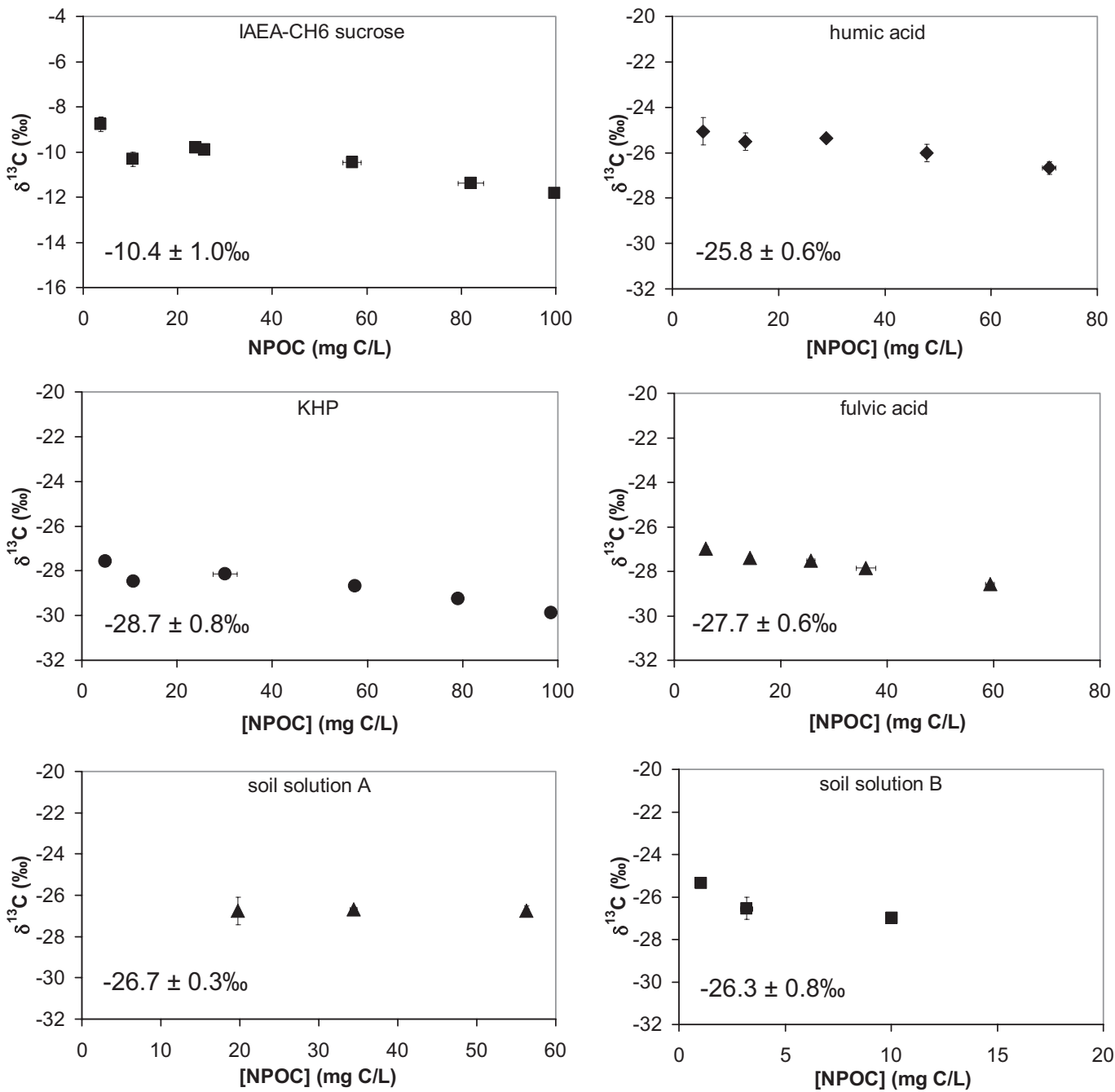

Figure 3. The $\delta^{13} \mathrm{C}$ value against the NPOC concentration for dilution series of six different solutions. Symbols and error bars represent mean \pm standard deviation (SD). The mean $\delta^{13} \mathrm{C}$ value $\pm \mathrm{SD}$ over the whole concentration range is also given.

could be removed successfully without significantly influencing the ${ }^{13} \mathrm{C} /{ }^{12} \mathrm{C}$ ratios or affecting the precision of the analysis. However, when using this NPOC method, one has to bear in mind that purgeable organic compounds can also be sparged out. ${ }^{10}$ Moreover, high molecular weight substances (e.g. humic acids) are insoluble below $\mathrm{pH} \mathrm{2,} \mathrm{so}$ acidification to remove the dissolved inorganic carbon from soil solutions can cause these base-soluble acids to precipi- tate. This makes it more difficult to inject a representative and homogeneous subsample. Furthermore, these precipitated compounds are more resistant to oxidation. ${ }^{7,10}$ In our analysis, however, the DOC concentration of the humic acid solution did not significantly decrease after acidification. Moreover, no precipitation was observed. This suggests that the NPOC treatment can be used for soil solutions containing humic acids as long as no excess amount of $\mathrm{HCl}$ is added.

Table 2. Comparison of the carbon concentration and $\delta^{13} \mathrm{C}$ value of solutions with and without additional inorganic carbon, measured on the HTC TOC-IRMS system before ('TC') and after acidifying and purging ('NPOC') (mean \pm SD)

\begin{tabular}{|c|c|c|c|c|c|}
\hline & \multicolumn{2}{|c|}{ TC analysis } & \multicolumn{2}{|c|}{ NPOC analysis } & \multirow[b]{2}{*}{$\mathrm{n}$} \\
\hline & $\begin{array}{c}{[\mathrm{TC}]} \\
-\mathrm{mg} \mathrm{C} / \mathrm{L}-\end{array}$ & $\begin{array}{l}\delta^{13} \mathrm{C} \\
-\%{ }^{\circ}\end{array}$ & $\begin{array}{c}{[\mathrm{NPOC}]} \\
-\mathrm{mg} \mathrm{C} / \mathrm{L}-\end{array}$ & $\begin{array}{l}\delta^{13} \mathrm{C} \\
-\%{ }^{\circ}\end{array}$ & \\
\hline IAEA-C6 sucrose & $21.4 \pm 0.4$ & $-10.3 \pm 0.2$ & $19.8 \pm 0.4$ & $-10.5 \pm 0.4$ & 5 \\
\hline IAEA-C6 sucrose $+\mathrm{HCO}_{3}^{-}$ & $36.4 \pm 0.8$ & $-8.2 \pm 0.1$ & $19.8 \pm 0.7$ & $-10.4 \pm 0.1$ & 5 \\
\hline Fulvic acid + & $13.0 \pm 0.2$ & $-26.1 \pm 0.2$ & $11.9 \pm 0.3$ & $-27.3 \pm 0.1$ & 3 \\
\hline Fulvic acid ${ }^{+}+\mathrm{HCO}_{3}^{-}$ & $28.9 \pm 0.3$ & $-14.3 \pm 0.2$ & $11.5 \pm 0.3$ & $-27.1 \pm 0.2$ & 3 \\
\hline Humic acid* & $22.6 \pm 0.1$ & $-24.14 \pm 0.03$ & $19.5 \pm 1.2$ & $-25.3 \pm 0.2$ & 3 \\
\hline Humic acid ${ }^{*}+\mathrm{HCO}_{3}^{-}$ & $37.3 \pm 0.8$ & $-16.2 \pm 0.3$ & $19.1 \pm 0.4$ & $-25.5 \pm 0.4$ & 3 \\
\hline
\end{tabular}

*Aldrich, cat. no. H 1675-2;

${ }^{+}$IHSS, Suwannee River Fulvic acid, 1R101F. 


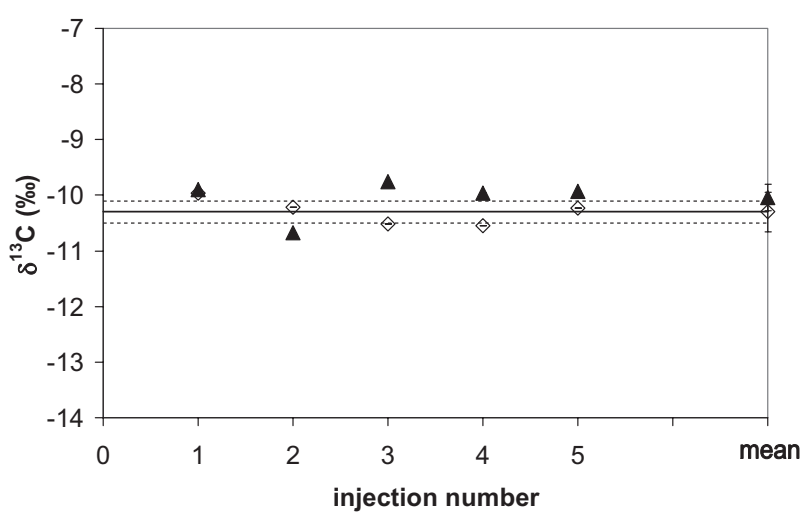

Figure 4. The $\delta^{13} \mathrm{C}$ signal of five analyses of an IAEA-C6 sucrose solution after the analysis of a $-23.3 \%$ beet sugar solution $(\diamond)$ or after the analysis of a $298 \%$ plant extract $(\boldsymbol{\Delta})$. The lines represent mean (solid line) $\pm S D$ (dotted lines) of the solution measured by the HTC TOC-IRMS set-up in the precision test (Table 1).

\section{Memory effect}

The injection of a beet sugar solution $\left(\delta^{13} \mathrm{C}=-23.7 \%\right.$ ) or an enriched sample $\left(\delta^{13} \mathrm{C}=340 \%\right)$ did not have any significant effect on the analysis of the subsequent IAEAC6 sucrose solution (Fig. 4). There was no significant difference between the first injection of the sucrose solution after the natural abundance and after the ${ }^{13} \mathrm{C}$-enriched sample, indicating the absence of a memory effect. The mean $\delta^{13} \mathrm{C}$ values of the five analyses, following the beet sugar or the ${ }^{13} \mathrm{C}$-enriched plant extract, did not significantly differ from each other (Duncan test, $\alpha=0.05$ ), nor from the value of the solid sample measured by EA-IRMS $(-10.6 \pm 0.2 \%)$. Since no cross contamination between samples was observed, the system appeared to be very robust for the analysis of natural abundance as well as enriched samples.

\section{System stability over time}

Over a period of 8.5 months, the internal reference sample was analyzed 33 times with a resulting NPOC concentration of $22.1 \pm 1.4 \mathrm{mg} \mathrm{C} / \mathrm{L} \quad\left(\right.$ mean $\pm \mathrm{SD}$ ), and average $\delta^{13} \mathrm{C}$ value of $-25.5 \pm 0.4 \%$. Because the internal reference was analyzed with less than half a delta value deviation over a period of more than 8 months, we concluded that with this set-up and the associated calculations for blank correction, samples could be analyzed with an acceptable stability over time.

\section{Preliminary tracer experiment with (enriched) soil solutions}

Neither the DOC concentration nor the $\delta^{13} \mathrm{C}_{\mathrm{DOC}}$ of the pore water of the control soil samples changed significantly during the incubation (Fig. 5). On the other hand, the addition of dried and cut cob leaves to soil samples caused an increase of the $\delta^{13} \mathrm{C}_{\mathrm{DOC}}$ to $1036 \pm 16 \%$ and of the DOC concentration to $632 \pm 69 \mathrm{mg} \mathrm{C} / \mathrm{L}$ at day 0 . Since the plant

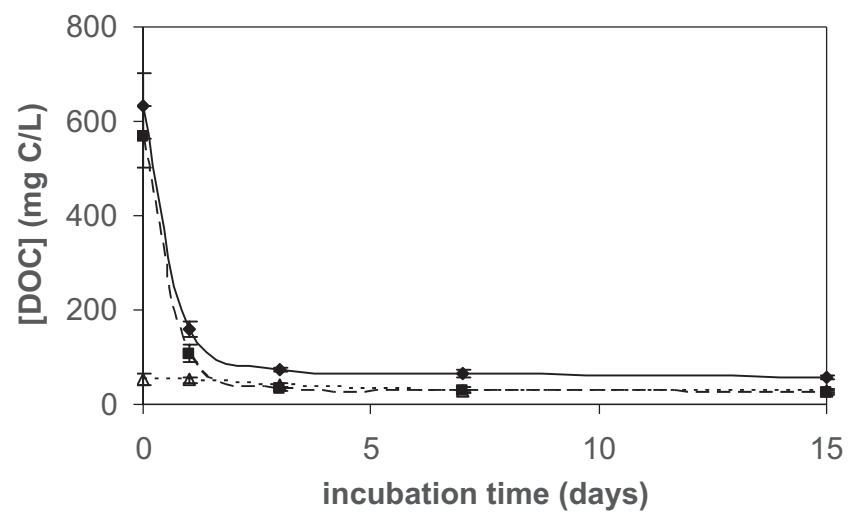

Figure 5. The decrease in time of the DOC concentration in the soil solution of control soil samples $(\Delta)$ and of soil samples to which enriched maize straw was added $(\diamond)$. The amount of DOC originating from the plant residues is also presented (ם). Symbols and error bars represent mean \pm standard deviation $(n=6)$.

residues were labeled, we could determine the contribution of maize-derived $\mathrm{C}$ to this DOC pulse as:

$$
f=\frac{\text { DOC }_{\text {plant }}}{\text { DOC }_{\text {total }}}=\frac{\delta^{13} \mathrm{C}_{\text {sample }}-\delta^{13} \mathrm{C}_{\text {control }}}{\delta^{13} \mathrm{C}_{\text {plant }}-\delta^{13} \mathrm{C}_{\text {control }}}
$$

As such, the plant-derived DOC concentration (Fig. 5) was determined by multiplication of the plant-originating fraction (Eqn. (3)) with the total DOC concentration in the samples. Approximately $4 \mathrm{~h}$ after the addition of plant residues, $92 \%$ of the DOC in the pore water of the soil samples was plant-derived. The DOC concentration decreased during the beginning of the incubation, but stabilized after 3 days. About $44 \%$ of the DOC left after 2 weeks originated from the maize straw. It could be calculated that, by adding dried maize straw to soil samples, around $5 \%$ of the plant carbon is released in the soil solution. After $24 \mathrm{~h}$ of incubation, only $1 \%$ of the plant $\mathrm{C}$ was left in the soil solution, so most of the released DOC was very quickly degraded or sorbed to the mineral phase. From this experiment, we concluded that our set-up could be used for the determination of the ${ }^{13} \mathrm{C} /{ }^{12} \mathrm{C}$ ratios of DOC in soil solutions at natural abundance as well as at enriched level. Moreover, the concentration and isotopic ratio of carbon could now be measured in the three different phases (solid, liquid, gas) of the soil which is a great advantage in tracer experiments with soil $\mathrm{C}$.

\section{CONCLUSIONS AND RECOMMENDATIONS}

In order to measure the ${ }^{13} \mathrm{C} /{ }^{12} \mathrm{C}$ ratios of organic carbon in soil solutions, an HTC TOC instrument was coupled with an IRMS instrument. Although some automated HTC TOCIRMS systems have already been developed, $, 8,11,12$ no results for the analyses of soil solutions or ${ }^{13} \mathrm{C}$-enriched samples have been reported. Because we wanted to analyze soil solutions containing refractory humic and fulvic acids and we only had small sample volumes, we 
preferred to convert DOC into $\mathrm{CO}_{2}$ gas by high-temperature combustion rather than by wet oxidation. The low $\mathrm{CO}_{2}$ concentrations, resulting from the combustion of small sample volumes, could be measured well by cryogenically trapping and focusing the gas stream from the TOC instrument before analysis by IRMS. We used the system to measure the ${ }^{13} \mathrm{C} /{ }^{12} \mathrm{C}$ ratios of DOC (NPOC), but with the same set-up the ${ }^{13} \mathrm{C} /{ }^{12} \mathrm{C}$ ratios of total and inorganic carbon can also be determined. Only a few modifications were necessary to couple a commercially available HTC TOC instrument with an IRMS instrument, using a cryotrapping device between the two instruments. The contribution of the blank in the coupled set-up was measured directly. For sample volumes of $160 \mu \mathrm{L}$, the system blank accounted for $0.05 \mu \mathrm{g} \mathrm{C}$ and the milliQ water for an additional $0.19 \mu \mathrm{g} \mathrm{C}$. Since the DOC concentration in most of our soil solution samples ranged from 10 to $50 \mathrm{mg} \mathrm{C} / \mathrm{L}$, the total blank contribution was between 15 to $1 \%$ of the sample response and a blank correction was recommended.

Based on the results of the performance tests, we concluded that the ${ }^{13} \mathrm{C} /{ }^{12} \mathrm{C}$ ratios of DOC in solutions with concentrations ranging from 1 to $100 \mathrm{mg} \mathrm{C} / \mathrm{L}$ could be measured with good precision (SD $\leq 0.6 \%$ ) and accuracy. Within this range, the system showed acceptable linearity; and the overall standard deviation between the measurements was less than or equal to $1 \%$. The accuracy, precision and linearity of the analysis were even better for samples with carbon concentrations between 10 and $50 \mathrm{mg} \mathrm{C/L}$, which is the concentration range wherein we generally analyze soil solutions. Within this range, the overall standard deviation was reduced to $0.4 \%$.

Test solutions, made by dissolving organic compounds in milliQ water, should be acidified and purged before analysis. Although the addition of acid can theoretically cause precipitation of hydrophobic molecules, ${ }^{7,10}$ acidifying and purging the samples did not affect the measurement of the ${ }^{13} \mathrm{C} /{ }^{12} \mathrm{C}$ isotopic ratio or the DOC concentration of our samples. Carry-over, which is known to be a problem in dry combustion systems, ${ }^{10}$ was tested for natural abundance as well as enriched samples and no significant memory effects were observed.

The analytical tests and the results of the preliminary experiment demonstrate that the system could be used, in a fully automated fashion, to determine the ${ }^{13} \mathrm{C} /{ }^{12} \mathrm{C}$ ratios of test and soil solutions. Only a few modifications were necessary to couple a commercially available HTC TOC instrument with an IRMS instrument, using a CRYOPREP system between the two instruments. However, if samples with concentrations less than $10 \mathrm{mg} \mathrm{C} / \mathrm{L}$ have to be analyzed with higher precision, the sample volume should be increased and the blank of the system should ideally be reduced. Panetta et al. ${ }^{12}$ found that changing the Pt-based catalyst to silica rods with cupric oxide reduced the blank significantly. Furthermore, for solutions which are prepared by dissolving components in milliQ water, we suggest pretreating the milliQ water and acid by UV exposure and $\mathrm{He}$ purging to further lower the blanks.

When analyzing the isotopic ratio of $\mathrm{CO}_{2}$, one has also to be cautious about interference from $\mathrm{N}_{2} \mathrm{O}$. In our set-up, a Poraplot-Q GC column is used to separate $\mathrm{CO}_{2}$ from $\mathrm{N}_{2} \mathrm{O}$; but better separation could be achieved by using a packed Porapak-Q column. ${ }^{18}$ However, interference from $\mathrm{N}_{2} \mathrm{O}$ can also easily be circumvented by placing a $\mathrm{Cu}$-filled reduction column at $640^{\circ} \mathrm{C}$ before the gas chromatograph.

\section{Acknowledgements}

This research was funded by the Onderzoeksfonds K.U. Leuven under the project number GOA/2006/07-TBA. We also would like to thank Andrew Park (SerCon Ltd., UK) for programming the software modifications, and two anonymous referees whose comments greatly improved this manuscript.

\section{REFERENCES}

1. Kalbitz K, Solinger S, Park JH, Michalzik B, Matzner E. Soil Sci. 2000; 165: 277.

2. Raymond PA, Bauer JE. Org. Geochem. 2001; 32: 469.

3. le Clercq M, van der Plicht J, Meijer HAJ. Anal. Chim. Acta 1998; 370: 19.

4. Fry B, Peltzer ET, Hopkinson CS Jr, Nolin A, Redmond L. Mar. Chem. 1996; 54: 191.

5. Gandhi H, Wiegner TN, Ostrom PH, Kaplan LA, Ostrom NE. Rapid. Commun. Mass Spectrom. 2004; 18: 903.

6. Buzek F, Paces T, Jackova I. Appl. Geochem. 2009; 24: 1686.

7. St-Jean G. Rapid. Commun. Mass Spectrom. 2003; 17: 419.

8. Bouillon S, Korntheuer M, Baeyens W, Dehairs F. Limnol. Oceanogr.: Methods 2006; 4: 216.

9. Osburn CL, St-Jean G. Limnol. Oceanogr.: Methods 2007; 4: 296.

10. Bisutti I, Hilke I, Raessler M. Trends Anal. Chem. 2004; 23 716.

11. Lang SQ, Lilley MD, Hedges JI. Mar. Chem. 2007; 103: 318.

12. Panetta RJ, Ibrahim M, Gélinas Y. Anal. Chem. 2008; 80: 5232.

13. Qian I, Mopper K. Anal. Chem. 1996; 68: 3090.

14. Peterson ML, Lang SQ, Aufdenkampe AK, Hedges JI. Mar. Chem. 2003; 81: 89.

15. Skoog A, Thomas D, Lara R, Richter K-U. Mar. Chem. 1997; 56: 39.

16. Chen W, Zhao Z, Koprivnjak J-F, Perdue EM. Mar. Chem. 2002; 78: 185.

17. Sharp JH, Benner R, Bennett L, Carlson CA, Dow R, Fitzwater SE. Limnol. Oceanogr. 1993; 38: 1774.

18. Beheydt D, Boeckx P, Clough TJ, Vermeulen J, Sherlock RR, Van Cleemput O. Rapid. Commun. Mass Spectrom. 2005; 19: 1365 . 